\title{
Functional Peculiarities of Lexical Syntagm in Technical Writing
}

\author{
Dr. Minoo Khamesian \\ PhD in Linguistics
}

\begin{abstract}
Admittedly, in the course of intellectual communication terms tend to be widely used for the expression of concepts and notions of a given branch of knowledge. The meaning or content of words used to express special phenomena or concepts, greatly constituted by the object itself, is a reflection of it in the writer's mind. The study was an attempt to disclose the functional peculiarities of technical writing on the lexical syntagmatic level of linguistic expressions, focusing on those derivatives, coinages, the creation or the very existence of which would be based on quite definite, well-fixed rules of combining morphemes according to the productive patterns of lexicology, i.e. rules determined by the lexical-morphological categories of the language under investigation, English as the Lingua Franca of science and technology. The analysis showed that in technical writing the presence of such derivatives, besides the need to name new scientific concepts, would have a tendency to acquire metasemiotic overtones. In other words, they might be generally formed by the authors under some contextual circumstances to give the utterance a more stressed effect and enhance the rhetorical impact likely to circulate in the related discourse community.
\end{abstract}

Key Words: coinages, lexical syntagm, rhetorical impact

\section{INTRODUCTION}

It is a general assumption that scientific communication is highly likely to be laden with terms for the expression of concepts and notions in a specific field. Nevertheless, all semiotic systems should ideally rely on the law of the sign, i.e. a one-to-one correspondence between plane of expression and plane of content, which means words as the fundamental unit of any language, English for Academic Purposes in this work, tend to be accompanied by a dialectical unity of form and content. In the course of scientific communication, to pursue precision and objectiveness, authors are believed to select words prioritized by accuracy, specificity, and concrete materiality.

We should hasten to add that English for science and technology, a tool for organized communication, tends to include some features, such as readability which entails simple, direct, and concise wording, and objectivity, which, on the other hand, does not mean that the writer must sound like an automaton. His presence in such a discourse, while likely to facilitate only evincing authorial integrity, is inevitable. The latter could also mean avoiding words of personal or emotional values and references, Akhmanova, 1985.

Otherwise stated, according to Khamesian 2013, scientific prose style could be considered a remarkably codified variety of linguistic usage emerging and developing altogether with scientific promotions and thoughts, implying a great deal of uniformity when generalizing this particular mode of communication. It seems as if the whole process would work on the shared code including terms proper, as well as various syntagmatic units.

As rather unanimously accepted, each genre tends to be regarded as an instance of a successful achievement of a specific communicative objective using conventionalized knowledge of 
linguistic and discoursal resources. Inasmuch as each genre in certain important respects would be a typical way of structuring a narrow world in terms of experience or reality, it could not be unlikely for the same experience or reality to call for a different way of construction, if one seeks operating in a different genre. Despite the undeniable fact that many professional writers still operate well within a broad range of generic rules and conventions, plenty of scientific writers tend to resort to some peculiarities to achieve effectiveness and originality in their writing.

In this regard, coinages are especially striking. They generally follow the easy flow of verbal sequences, however, they challenge the mind to take in the referential meaning. According to Galperin 1977, providing the neologism designates a new notion derived from scientific and technical research, the aesthetic effect would not be considerable. Otherwise stated, the intellectual impact would surmount the emotional one. Nonetheless, coinages aiming to introduce additional meanings resulting from an aesthetic re-evaluation of the given concept might be capable of functioning as a stylistic device.

Analysis

Scientific prose style comprises its own peculiarities, being familiar with which can be considered an indispensable part of EAP. To analyze the functional peculiarity of lexical syntagm, i.e. coinages, in technical writing linguostylistically, the following sentences were extracted from online journals of different engineering spheres, i.e. civil engineering, mechanical engineering, etc.

However, before embarking on the analysis, it does not seem unreasonable to resort to Galperin's classification of coining. As he explains, firstly, newly coined words, which would designate newborn concepts, might be called terminological coinages. He refers to the second type as those coined to meet their creators' seeking expressive utterance named stylistic coinages. The other one which he calls the nonce - word remains on the outskirts of the literary language, hence not scoped in this work ${ }^{1}$.

\section{SAMPLES}

- The use of superplastizers is essential to produce flowing concretes. Superplastizers increase the flowability as well as contribute to improve the compressive strength of concrete.

- Most of the Yield criterions are defined in terms of stress invariants. Here J , J , J are first, second and third stress invariant and J' is second stress in- 1232 variant of deviatoric stress components.

- At any future point of time, when it is desired to assess the health of structure, the conductance and susceptance signatures are acquired and further utilized for damage detec- tion and quantification.

- The instantaneous reference streams are obtained by in-stage supply reference currents from the unit vector signal, and quadarature supply reference currents. When the reference supply streams are created, a transporter Over AC terminal voltage is considered the plentifulness of the quadarature segment of supply reference currents.

- In urban areas these spaces have the potential to function as temperature amenizadores (climate control)-------.

- Since the flash point of vegetable oils in the raw form was comparatively higher then diesel fuel, therefore, it calls for transesterification so that the diesel engine could be safely run on vegetable oils blends. 
- Results show that if the suction rate is sufficiently high, relaminarization of the flow occurs almost immediately downstream the suction location.

- Major pollutants in textile waste waters are suspended solids, oxidizable matter, acidity and other soluble substances.

- There are a limited number of papers that present the closed-form or analytical solution for the quasi-static porothermoelasticity problems.

- The UPS is a unitcomposing of a range of solid-state devices, interconnected-----.

- Transesterification is the process of using an alcohol (e.g. methanol or ethanol) in the presence of a catalyst, such a

- Due to the orthogonality of function $\mathrm{H}$, every piece-wise continuous function, such as---

To start, the concept of communicative competence as written time and again presupposes the language user's ability, scientific writers in our case, to express exactly what they mean by applying linguistic devices appropriate to the medium of their discourse community, including the knowledge of rhetoric. This can be due to the fact that scientific discourse is characterized by some rhetorical features, clearly manifested in the structure and composition of scientific texts ${ }^{2}$.

Interestingly, the highlighted coinages are not likely to be fixed in dictionaries as commonly used words. According to the allo-emic principle of American descriptive linguistics ${ }^{3}$, the suffix -eme means a structural element, or a structural unit of language. The prefix allo-, used generally in linguistics to refer to any noticeable variation in the form of a linguistic unit which would not affect its functional identity in the language, indicates that the segment or segments of the units under analysis are variants, different manifestations of one and the same -eme. In other words, whenever, allo-emic terminology is used, the underlying message is guaranteed a one-to-one correspondence, i.e. it is unambiguously and unmistakenly correlated with a certain combination of discernible signals in such a way that at the receiving end the combination will make it possible to reconstruct the original message.

Furthermore, research has shown that derivative words are more preferable means of any linguostylistic study, in addition to the study of functional styles, for they represent both lexical and syntactic relations. Therefore, they emphasize the functional motivation of the speech (Jahukyan, 2003).

What is noticeable is 'terminological coinage', e.g. superplastizers, transestrification, relaminarization, porothermoelasticity, amenizadores, quadarature. These coinages could be meeting the demand for terms necessary to name a finding, innovation, process, etc. which is highly prevalent in engineering texts. This could be called novelty resulted from requirements in science and technology.

However, we cannot but be affected by some stylistic coinages, e.g. plentifulness, susceptance, descritize, oxidizable, decolorization. The point worth continuing with is a tendency to acquire metasemiotic overtones, as it seems that the authors created them under some contextual circumstances to give their work a more stressed effect and enhance the rhetorical impact on their target audience, not only by their novelty but by a more elaborate language effect, which would adequately convey the author's idea to the mind of the reader, hence novelty in addition to force. Take, 'plentifulness' for example to replace 'abundance'. The author might have intended to show something resulted from their work not already existing to make it more expressive, to produce certain impact on the reader connotatively, rather than to merely convey some intellectual information. 
Bloomfield 1939 to explain the benefits of this scientific way of communicating maintains: "The use of language in science is specialized and peculiar. In a brief speech the scientist manages to say things which in ordinary language would require a vast amount of talk. His hearers respond with great accuracy and uniformity. The range and exactitude of scientific prediction exceed any cleverness of everyday life: the scientist's use of language is strangely effective and powerful. Along with systematic observation, it is this peculiar use of language which distinguishes science from non-scientific behavior." (P. 1)

Obviously, in both types of the coinages, an explicit correspondence between expression and content can be noticed, which would, needless to say, enable the authors to avoid misunderstanding and ambiguity. Clearly, the absence of emotionally coloured syntagms would cause absolute convertibility of the purport of the text, for, as widely shown, the reader should not have stranger associations; they should not read between the lines, and be admired by the game of words and calamburs (Akhmanova and Idzelis, 1976).

It seems the syntagms are created by the author at the moment of writing, hence having a special lexical form and promoting the function of impact on the reader. However, when in a given field the coinage has already realized itself, it tends to become monolexemic unit, i.e. being established as stable individual lexeme in the language, not just syntagm created for particular circumstances. Due to this fact, many coinages with distinguished lexical morphological category would become semantically isolated, as time goes by, i.e. a stable unit with an informative function. In this regard, Vinogradov 1941 justly puts, "...The turning point in the semantic history of many words is the new, vividly expressive, figurative, individual use of them. This new and genuinely artistic application of a word, if it is in conformity with the general tendencies of the semantic development of the language, not infrequently predetermines the further semantic development of the word." (p.8)

It is worth adding that juxtaposing the semantic and metasemiotic values of the coined elements, the authors have intended to make these lexical units accessible to their readers and increase their emphatic effects. The accepted belief is unlike what we face in fictive prose, where the emotive-expressive-evaluative overtones make an aesthetic impact on the reader, here they definitely express the author's attitude, their evaluation of the stated facts and documents. Thus, according to Galperin 1977, the stylistic effect derived from coinages would generally lie on the ability of the coiner's mind to perceive novelty at the background of the familiar, to the extent that the sharper the contrast, the more obvious the effect. Those slight alterations emanated from extensions of the original meaning, being virtually imperceptible, are likely to create a stylistic effect providing that the reader is well versed in discriminating nuances of meaning.

With regard to terms, When using them, our mind would immediately associate them with particular nomenclatures as being directly linked to the concept they are supposed to denote. Thus, terms, contrary to other words, tend to channel the mind towards the essential quality of the thing, phenomenon or action as perceived by the scientist in the light of their own conceptualization.

As we can see, the creation of these words on the lexical syntagmatic level of linguistic expression would be generally based on the quite definite, well-fixed rules of combining morphemes according to productive patterns, e.g. oxidizable, i.e. oxid + ize + able, or plentifulness, i.e. plenty + ful + ness, to name but a few. Those of marked category forms of all morphological oppositions, tend to be considered as having 'rhetorical functions', acquiring 
metasemiotic overtones. We cannot but appreciate the role of rhetorical forms in shaping realities. Not as stylistic ornamentation but as persuasive discourse, in actual fact, all discourse tends to be rhetorical to a great extent. When such derivatives are "breathed to life" their semantic context may be complicated by metasemiotic connotations. They are coined when a language user strives for originality and requires to embellish their speech with something unique, singular, or exceptionally expressive (Muradyan, 2009). Thus, a lexical-morphological category will serve to satisfy such an impulse together with other expressive means.

We should acknowledge Ullmann 1951 for what he puts, "All scientists are linguists to some extent. They are responsible for devising a consistent terminology, a skeleton language to talk about their subject matter (p. 107). Studies have also shown that the derivative words are more preferable means of any linguostylistic study, as well as the study of functional styles, as they represent not only lexical but also syntactic relations (Jahukyan, 2003), therefore, emphasizing the functional motivation of the speech. Derivative words tend to be marked for being used vastly and their function of impact being predominant in speech.

\section{CONCLUSION}

Our analysis on the functional peculiarity of lexical syntagm in technical writing revealed that in line with what the term semiotics denotes, the coined words would carry the quality of being directly and unambiguously apprehended by the users of the style, keeping with the law of the sign, i.e. a one-to-one correspondence between expression and content.

Consequently, we cannot but say that coining new words in engineering research articles would firstly arise from the need to designate new concepts which result from the development of science. Otherwise stated, the need to express nuances of meaning called forth by a deeper understanding of the nature of the phenomenon in question could bring about such instances. Furthermore, we might conclude by saying that every scientific description tends to presuppose a certain framework reflecting the general direction of the description, its conceptual basis, the goal to be achieved as well as the theoretical inclinations and the linguistic world outlook of a particular author, hence rhetorical impacts. We should bear in mind that rhetoric is not merely the representation of thoughts but it is undoubtedly an impact on how authors think, which deserves serious attention. It is the responsibility of scientific writers to be familiar with such academic proficiency since their findings would not speak for themselves, and the writers should argue for their existence.

Inasmuch as a vast number of such syntagms are typical of technical writing, in EAP, not just linguistic proficiency but awareness of what a major role rhetoric can play to help academic writers to communicate their messages seems crucially important. We should acknowledge that research articles cannot be unproblematic manifestations of knowledge, but subtle rhetorical constructions with degrees of epistemological implications.

\section{Notes}

1- See Galperin, Stylistics. 1977. PP. 92-94.

2- See Khamesian, Rhetorical Impact through Hedging Devices in the 'Results and Discussion' Part of a Civil Engineering Research Article. 2015.

3- Further elaborated by G. Hammarstrom, and K. Pike.

\section{References}

Akhmanova O. S., Idzelis R. F. What is the English We Use. Moscow: Moscow University Press, 1978.

Akhmanova, O. Terminologies and Terminology and Related Fields. Dedicated to Helmut Felber-Wien, 1985. 
Bloomfield, L. 1939. Linguistic aspects of science. Chicago: University of Chicago Press.

Galperin I. R. Stylistics. Moscow "Higher School", 1977.

Jahukyan, G. B. \& Sakayan, D. A Universal Language Theory: Prolegomena to Substantional Linguistics. Published by Caravan Books, 2003.

Khamesian, M. Functional Approach to English for Engineering (with special reference to Iranian academic context). Lambert Publication; Online Book, 2013.

Khamesian, M. Rhetorical Impact through Hedging Devices in the 'Results and Discussion' Part of a Civil Engineering Research Article//Advances in Language and Literary Studies, 2015, vol. 6, N 6, pp. 183-186.

Vygotsky L.S. Thinking and Speech. New York: Plenum Press, 1987.

Muradyan G. Syntagmatics of Nominative Collocations in Modern English Essay // Armenian Folia Anglistika, International Journal of English Studies. Yerevan: Lusakn, 2009, vol. 1, N 5, pp. 6-16.

Ullmann S. Words and their Use. Frederick Muller, Ldn, 1951.

Vinogradov V. V. The Style of Pushkin. M., 1941, pp. 8-9.

\section{INTERNET SOURCES}

Asian Journal of Civil Engineering, Building and Housing, 2016. http://sid.ir/en/VEWSSID/__pdf/103820110602.pdf

The International Journal of Aerospace and Mechanical Engineering, 2016. http://www.waset.org/journals/ijmae/v6/v6-8.pdf

The International Journal of Electronics and Electrical Engineering, 2016. http://interscience.in/ijeee.html 